\title{
Photo-Physical Properties of Stilbine-3 (STB-3) Laser Dyes Embedded in Sol-Gel Glasses
}

\author{
Laxman V. Jathar¹, Dilip G. Achalawat¹, Jayraj R. Rane², Aparna V. Deshpande², Shaila M. Wagle ${ }^{3}$ \\ ${ }^{1}$ Department of Physics, R. D. National College, Mumbai University, Mumbai, India \\ ${ }^{2}$ Department of Physics, Institute of Chemical Technology, Mumbai University, Mumbai, India \\ ${ }^{3}$ Department of Physics, Kishinchand Chellaram College, Mumbai, India \\ Email: laxmanjathar@gmail.com, achlawat.dilip@gmail.com, jayrajrrane@yahoo.co.in, aparna.vijay.deshpande@gmail.com, \\ shaila_wagle@yahoo.com
}

How to cite this paper: Jathar, L.V., Achalawat, D.G., Rane, J.R., Deshpande, A.V. and Wagle, S.M. (2016) Photo-Physical Properties of Stilbine-3 (STB-3) Laser Dyes Embedded in Sol-gel Glasses. New Journal of Glass and Ceramics, 6, 64-74. http://dx.doi.org/10.4236/njgc.2016.64008

Received: December 9, 2015 Accepted: October 15, 2016

Published: October 18, 2016

Copyright $\odot 2016$ by authors and Scientific Research Publishing Inc. This work is licensed under the Creative Commons Attribution International License (CC BY 4.0).

http://creativecommons.org/licenses/by/4.0/ c) (i) Open Access

\section{Abstract}

Solid-state tunable dye laser materials developed by incorporation of stable laser dye molecules into solid host matrices like polymers, organically modified silicates (ORMOSILS) and porous sol-gel glasses. These materials have technical advantages such as compactness, better manageability and suitability for field measurement. The recent research work with highly porous sol-gel glasses having good transparency in UV-Near UV region used as solid host for solid-state dye laser materials has attracted a great deal of attention because of its high potential utility than polymers. Two different procedure's are used for incorpoerating the Stilbine-3 (STB-3) laser dyes into porous sol-gel matrices such as dope or dip methods. In dope method dye is mixed at the sol state and drying is carried out afterward; while in dip method matrix is first prepared and the matrix is dipped in desired dye solution. After preparation of these dye embedded sol-gel glasses we studied their spectroscopic properties of using absorption and fluorescence spectroscopy. Along with spectroscopy properties, the studies for longevity or the shelf life and lasing action of these materials were carried out. Laser dye STB-3 incorporated in sol-gel glass samples shows the same result as in methanolic solution.

\section{Keywords}

Sol-Gel Glass, Laser Dye , Stilbine-3 (STB-3)

\section{Introduction}

In recent years, more efforts have been devoted to incorporate organic laser dyes into various host matrices, with the goal of developing solid-state dye laser materials [1]-[4] 
that could possibly replace liquid dye lasers. Compared with liquid dye lasers, solidstate dye lasers have many advantages such as non-toxic, non-flammable, non-volatile compact and better mechanically and thermally etc. [1]-[5]. Solid-state tunable dye laser materials can be developed by incorporating stable laser dye molecules into solid host matrices like polymers, silica gels, xerogels, organically modified silicates (ORMOSILS) and sol-gel glasses [4]-[25].

Coumarin and stilbene-3 (STB-3) laser dyes are very efficient laser dyes for the spectral response in the blue-green region of the electromagnetic spectrum [26]-[50]. Several coumarin laser dyes have been widely studied in various solvents and solid hosts. [6] [26]-[47]. However very few reports are available on photophysical properties of STB-3 in solid host matrices [22] [25]. The photophysical properties of laser dyes provide basic information for their use in different applications which in turn depend on the molecular structure of the dye.

The lasing action of dye depends on its photophysical properties [18] [19] [48]-[50]. The high value of extinction coefficient and fluorescence quantum yield of a laser dye is favourable for good lasing performance. Therefore, it is necessary to pay more attention to investigate the photophysical properties of dye/sol-gel elements. With these objectives we are reported Spectroscopic properties of prepaired STB-3 impregnated sol-gel solid samples using three distinct methods.

\section{Experimental}

\subsection{Preparation}

Molecular weight of Stilbene-3 (STB-3)

Stilbene 3 (STB3); Lambda Physik (Laser grade) Mol. wt. 562.62.

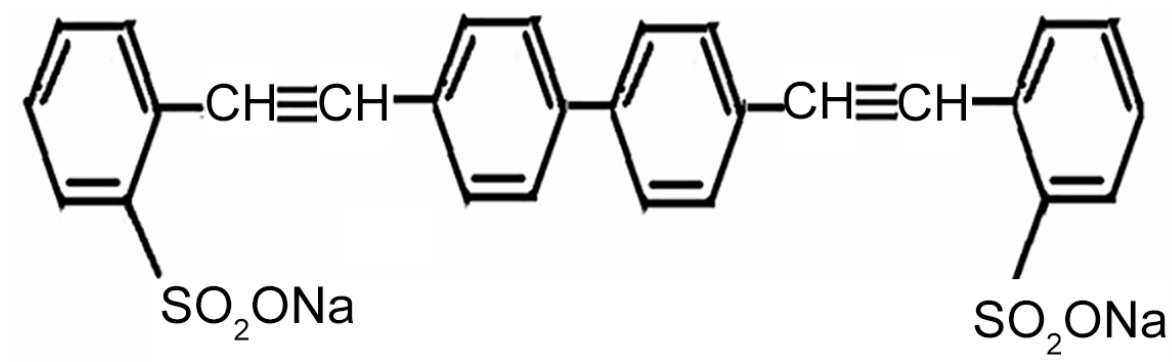

Molecular structure of Stilbene-3 (STB-3).

As we know the preparation of sol-gel is a two step process involving hydrolysis and polycondensation of metal alkoxide in presence of a catalyst. The sol-gel materials are prepared in the present work by carrying out hydrolysis and polycondensation of tetraethylorthosilicate (TEOS) using $\mathrm{HCl}$ as catalyst.

The materials were prepared by employing three different methods.

1) Method I: Using $\mathrm{HCl}$ as catalyst and glycerol as DCCA.

A sol was prepared by mixing $11.2 \mathrm{ml}$ TEOS, $6 \mathrm{ml} \mathrm{MeOH}, 9 \mathrm{ml}-\mathrm{H}_{2} \mathrm{O}, 1.0 \mathrm{ml} \mathrm{HCl}(0.1$ $\mathrm{N})$ as catalyst and $10 \mathrm{ml}$ glycerol as DCCA to reduce the cracking of monoliths during 
drying under magnetic stirring at room temperature. After 17 hours of stirring, $3.5 \mathrm{ml}$ sol was poured in the rectangular polystyrene cuvettes of size $(4.5 \times 1.0 \times 1.0) \mathrm{cm}^{3}$. The cuvettes were sealed with teflon tape to ensure slow drying of sol, which decreases the probability of cracking in solid. Drying and aging of gel were carried out at room temperature in clean and controlled environment.

After about 2 months from the date of preparation, solid blocks were obtained in the form of parallelopipeds with dimensions $(0.8 \times 0.8 \times 2.0) \mathrm{cm}^{3}$. These glass samples were immersed in $\mathrm{MeOH} / \mathrm{H}_{2} \mathrm{O}$ (50:50 by volume) for 16 hours and then subsequently in 15 $\mathrm{ml}$ methanolic solution of STB-3 dye of known concentration for one hour. After removing the samples from the solution they were dried at room temperature. After 15 days of drying the surface of the samples gets dried so that it is handable and can be subjected to various measurements.

2) Method II: Using $\mathrm{HCl}$ as catalyst at $60^{\circ} \mathrm{C}$ and drying at room temperature.

A sol was prepared by mixing $78 \mathrm{ml}$ TEOS, $102 \mathrm{ml}-\mathrm{H}_{2} \mathrm{O}, 2.4 \mathrm{ml} \mathrm{HCl}$ as catalyst under magnetic stirring at $60^{\circ} \mathrm{C}$ temperature for 1 hour. After 1 hour stirring, $3.5 \mathrm{ml}$ sol was poured in the rectangular polystyrene cuvettes and then sealed with teflon tape. Drying and aging of gel were carried out at room temperature in clean and controlled environment.

After about 20 days from the date of preparation, solid blocks were obtained in the form of parallelopipeds with dimensions $(0.8 \times 0.8 \times 2.8) \mathrm{cm}^{3}$. These glass samples were given dip treatment by immersing them in $\mathrm{MeOH} / \mathrm{H}_{2} \mathrm{O}$ (50:50 by volume) for different intervals of time such as 1 hour, 4 hours, 8 hours, 12 hours and 16 hours and then subsequently in methanolic solution of STB-3 dye of known concentration for one hour. After removing the samples from the solution they were dried at room temperature. After 5 days of drying the surface of the samples gets dried so that sample is handable and can be subjected to various measurements.

3) Method III: Using $\mathrm{HCl}$ as catalyst at $60^{\circ} \mathrm{C}$ and heated at $600^{\circ} \mathrm{C}$ temperature for 3 hours.

A sol was prepared by mixing $78 \mathrm{ml}$ TEOS, $102 \mathrm{ml}-\mathrm{H}_{2} \mathrm{O}, 2.4 \mathrm{ml} \mathrm{HCl}$ as catalyst under magnetic stirring at $60^{\circ} \mathrm{C}$ temperature for 1 hour. After stirring, $3.5 \mathrm{ml}$ sol was poured in the rectangular polystyrene cuvette and then sealed with teflon tape. Drying and aging of gel were carried out at $60^{\circ} \mathrm{C}$ temperature in heating blocks. After about 4 days from the date of preparation, solid blocks were obtained in the form of parallelopipeds with dimensions $(0.6 \times 0.6 \times 1.7) \mathrm{cm}^{3}$. These glass samples were given heat treatment by heating in programmable microwave furnace at $600^{\circ} \mathrm{C}$ for 3 hours and then subsequently they were cooled and kept at room temperature for one day and then the blocks were immersed in $15 \mathrm{ml}$ methanolic solution of dye of known concentration for one hour. After removing the samples from the solution they were dried at room temperature. After 3 days of drying the surface of the samples gets dried so that it is handable and can be subjected to various measurements.

The number density of dye doped molecules in the solid host was calculated by difference method from the optical density (OD) of absorption of dye solution before and after dipping of the glass sample. The desired number density of dye molecules in solid 
host can be obtained by dipping of glass samples in varied concentration of methanolic solution of STB-3dye. The dried solids obtained by all the above methods were visually of good surface finish with plane parallel side faces. They were used directly for spectroscopic and laser studies without any polishing of the faces.

\subsection{Absorption/Fluorescence Measurement}

The absorption spectra of STB-3 dye doped samples were recorded with respect to undoped glass sample by a conventional Spectrophotometer. The fluorescence spectra were recorded using an assembled fluorimeter with front surface excitation emission geometry. Fluorescence spectra of STB-3 impregnated sol-gel samples prepared by various methods and STB-3 in methanol were scanned at the same excitation wavelength $(350 \mathrm{~nm})$. All the recorded spectra were corrected for the photomultiplier and monochromator sensitivities. The fluorescence intensity (FI) of the dye embedded solid was normalized with the fluorescence intensity of the methanolic solution of the dye to obtain the relative fluorescence intensity.

After measurement of the photophysical properties including fluorescence lifetime, the dye impregnated sol-gel samples prepared by various methods were subjected to laser study under nitrogen laser pumping at $337.1 \mathrm{~nm}$ at the rate of $1.67 \mathrm{~Hz}$ in transverse dye laser cavity.

\section{Results and Discussion}

\subsection{Absorption/Fluorescence Properties}

Figures 1(a)-1(c) and Figures 2(a)-2(c) show the absorption and fluorescence spectra of STB-3 dye doped sol-gel glass samples prepared by Method I, Method II and Method III respectively with increasing drying time. It represents the typical behavior of these solids which is observed for all the concentrations of the dye studied in the present work. The shape of the spectra are similar to those in alcoholic solution suggesting existence of similar forms of dye molecule in the solution and solids. All STB-3 doped solid glass samples prepared by Method I, II and Method III having number densities of the order of $10^{15} / \mathrm{cm}^{3}$ to $10^{17} / \mathrm{cm}^{3}$ show single absorption peak peaking at $345 \mathrm{~nm}, 344$ $\mathrm{nm}$ and $348 \mathrm{~nm}$ respectively. As the drying time increases there is a decrease in the optical density (OD) value of main absorption peak at $345 \mathrm{~nm}$ and $344 \mathrm{~nm}$ for Method I and Method II samples respectively. But in case of samples prepared by Method III no such change in OD value is observed as drying time increases.

Also slight blue shift $(2 \mathrm{~nm})$ is observed in absorption maximum wavelength after 240 days of time of drying for all three types of STB-3 embedded sol-gel glasses. The fluorescence intensity (FI) also decreases with the lapse of time of preparation for Method I and Method II prepared samples, while no change in fluorescence intensity is observed in samples prepared by Method III as the drying time increases as shown in Figure 2(c). However the observed changes in absorption and fluorescence properties with increasing drying time are very less in samples prepared by Method II as compared to samples prepared by Method I. 


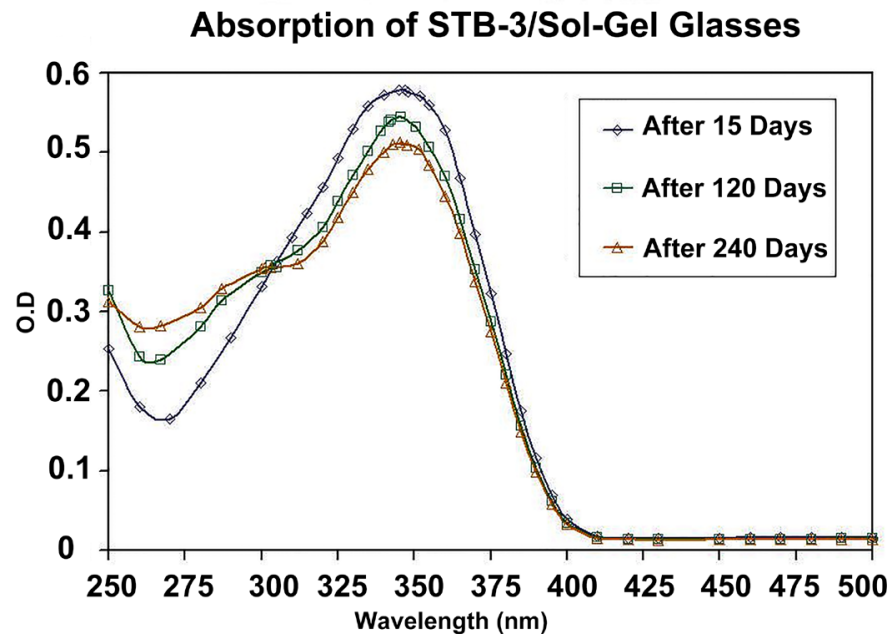

(a)

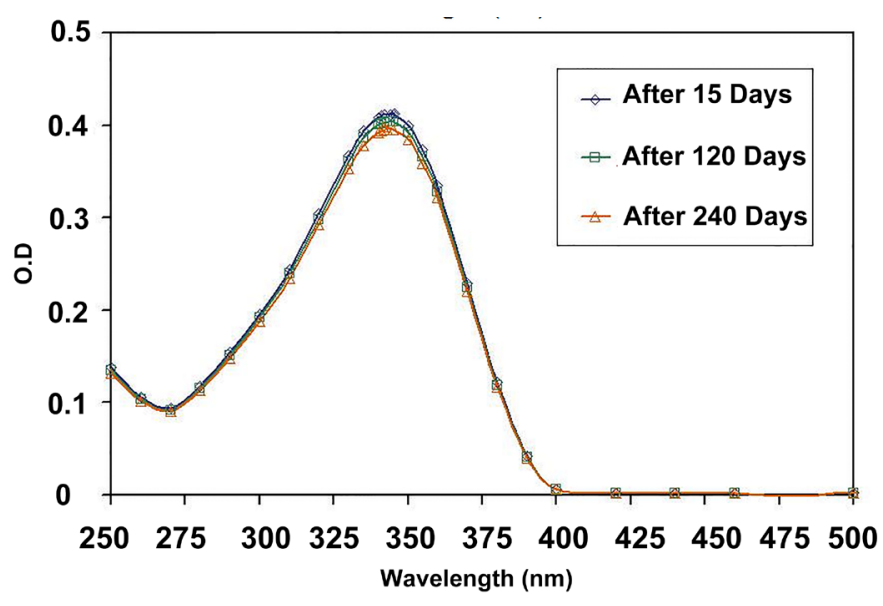

(b)

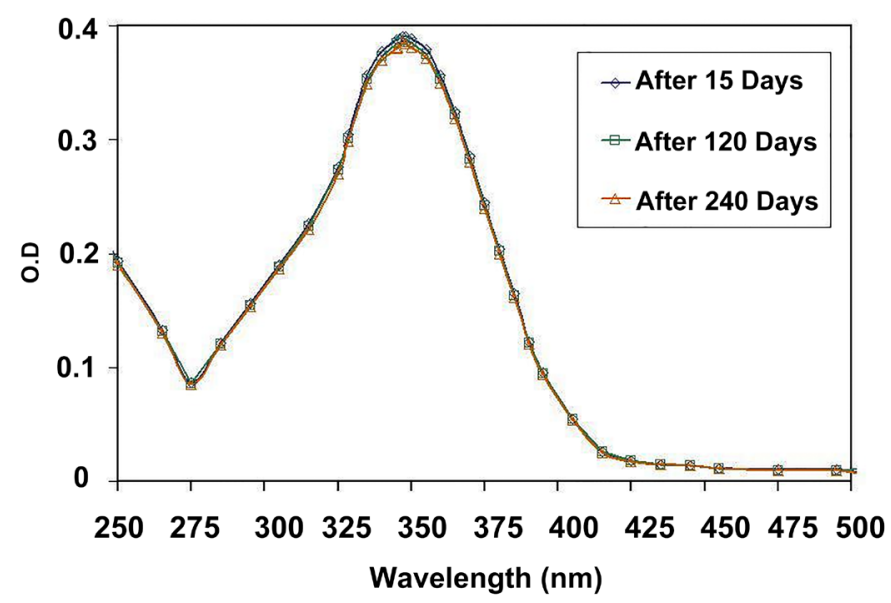

(c)

Figure 1. Absorption spectra of STB-3 containing sol-gel glass sample (a) Method I; (b) Method II and (c) Method III (no. density Method I: $1.12 \times 10^{16}$ per $\cdot \mathrm{cm}^{3}$; Method II: $7.50 \times 10^{15}$ per $\cdot \mathrm{cm}^{3}$; Method III: $6.62 \times 10^{15} \mathrm{per} \cdot \mathrm{cm}^{3}$ ). 
Fluoresecence of STB-3/Sol-Gel Glasses

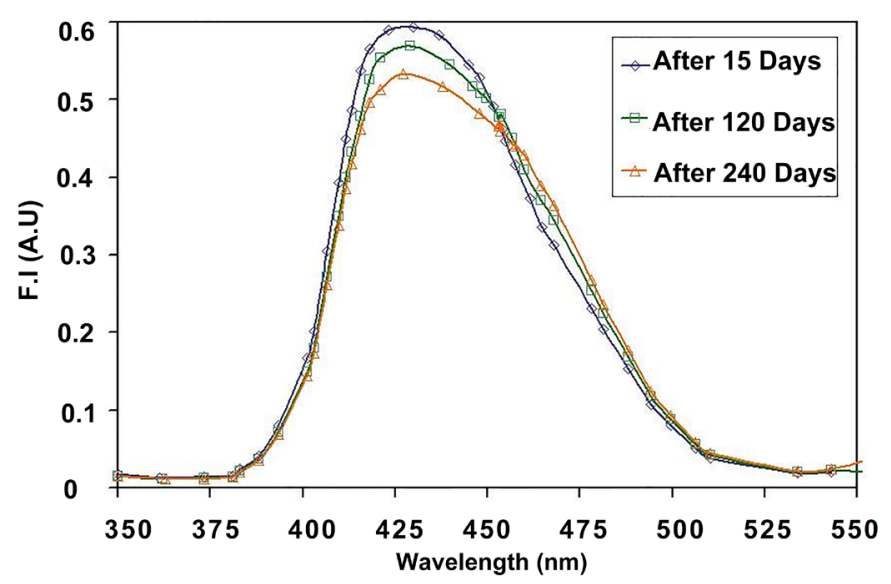

(a)

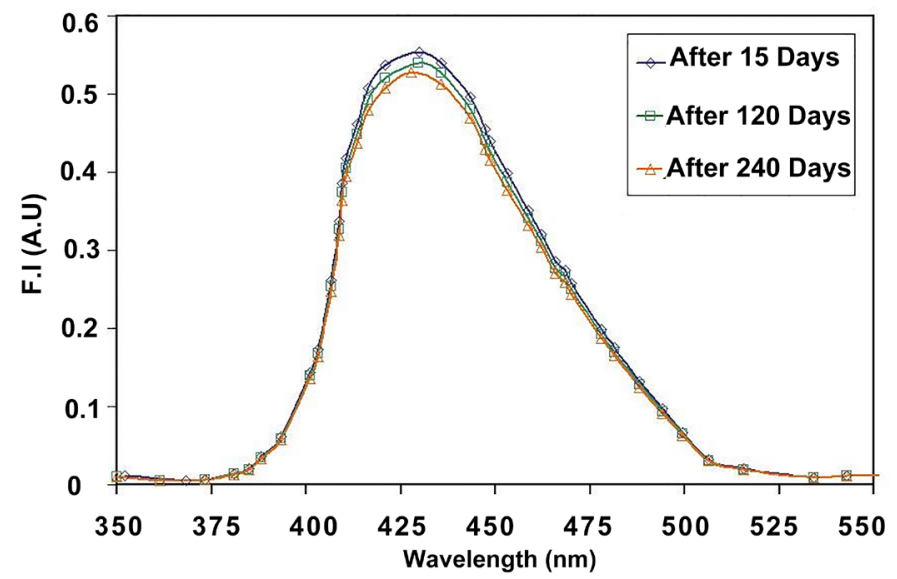

(b)

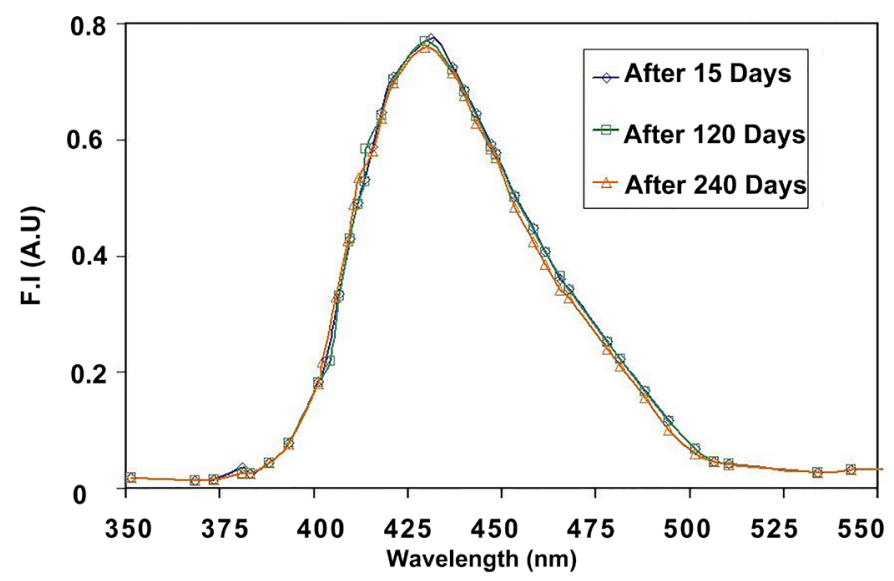

(b)

Figure 2. Fluorescence spectra of STB-3 containing sol-gel glass samples (a) Method I; (b) Method II and (c) Method III (no. density Method I: $8.52 \times 1016$ per $\mathrm{cm}^{3}$; Method II: $6.35 \times 1016$ per $\cdot \mathrm{cm}^{3}$; Method III: $1.32 \times 1017 \mathrm{per} \cdot \mathrm{cm}^{3}$ ). 
Table 1 lists the absorption properties of STB-3 in sol-gel blocks as well as in methanol with low concentration of the dye (number density of the order of $10^{15} \mathrm{per} \cdot \mathrm{cm}^{3}$ ). The absorption wavelength maxima $\left(\lambda_{\mathrm{a}}\right)$ for sample prepared by all the three methods are little blue shifted as compared to that in methanol. The extinction coefficient $(\varepsilon)$ of STB-3 in solid prepared by Method I and Method II are less compared to that in solution, where as in solids prepared by Method III it is more than that in solution. But the order of magnitude of $\varepsilon$ value is same for all the samples.

The changes observed in the fluorescence spectra of solid glass blocks with increasing dye concentrations (number densities of dye molecules of the order of $10^{15}-10^{18}$ per. $\mathrm{cm}^{3}$ of the solid) are depicted in Table 2 . The fluorescence wavelength $\left(\lambda_{\mathrm{f}}\right)$ of the dye doped solids is between $430-434 \mathrm{~nm}$ which is slightly blue shifted compared to that in alcoholic solution $(435 \mathrm{~nm})$. The FWHM increases initially as the concentration of the dye increases but decreases again for the higher number density samples. The fluorescence intensity (FI) also first increases and then decreases as the concentration of the dye in solid increases which is due to concentration quenching [30]-[45].

Table 1. Absorption properties of STB-3/sol-gel glass samples in comparison with STB-3/MeOH.

\begin{tabular}{cccc}
\hline & No. density $\left(\times 10^{15} \mathrm{~cm}^{-3}\right)$ & $\lambda_{\mathrm{a}}(\mathrm{nm})$ & $\varepsilon \times 10^{-4}\left(1 \mathrm{~mole}^{-1} \mathrm{~cm}^{-1}\right)$ \\
\hline STB-3/MeOH & 4.93 & 351 & 5.89 \\
Method I & 8.69 & 345 & 5.16 \\
Method II & 7.32 & 344 & 5.49 \\
Method III & 5.20 & 347 & 5.96 \\
\hline
\end{tabular}

Uncertainty $1 \mathrm{~nm}$ in $\left(\lambda_{\mathrm{a}}\right)$.

Table 2. Fluorescence properties of STB-3/sol-gel glass samples with different concentrations.

\begin{tabular}{|c|c|c|c|}
\hline No. density $\left(\mathrm{cm}^{-3}\right)$ & $\lambda_{\mathrm{f}}(\mathrm{nm})$ & FWHM $\left(\mathrm{cm}^{-1}\right)$ & FI (A.U.) \\
\hline \multicolumn{4}{|c|}{ Method I } \\
\hline $6.78 \times 10^{15}$ & 431 & 875 & 0.20 \\
\hline $8.52 \times 10^{16}$ & 431 & 1265 & 0.59 \\
\hline $3.80 \times 10^{17}$ & 432 & 1386 & 0.82 \\
\hline $5.51 \times 10^{18}$ & 434 & 919 & 0.32 \\
\hline \multicolumn{4}{|c|}{ Method II } \\
\hline $4.96 \times 10^{15}$ & 430 & 812 & 0.30 \\
\hline $9.51 \times 10^{16}$ & 431 & 1206 & 0.78 \\
\hline $7.96 \times 10^{17}$ & 432 & 1219 & 0.75 \\
\hline $6.31 \times 10^{18}$ & 433 & 829 & 0.42 \\
\hline \multicolumn{4}{|c|}{ Method III } \\
\hline $5.18 \times 10^{15}$ & 432 & 753 & 0.51 \\
\hline $7.62 \times 10^{16}$ & 432 & 1086 & 0.88 \\
\hline $5.91 \times 10^{17}$ & 433 & 1320 & 0.97 \\
\hline $4.44 \times 10^{18}$ & 434 & 896 & 0.51 \\
\hline
\end{tabular}

Uncertainty $1 \mathrm{~nm}$ in $\left(\lambda_{\mathrm{f}}\right) ; 0.05$ in $(\mathrm{FI})$ 
Samples prepared by method I and II show that the FI values are lower than those observed for samples prepared by Method III. This may be due to the presence of some residuals along with acid in Method I and Method II samples whereas most residual solvent/chemicals are coming out from the Method III samples during heating. The absorption and fluorescence spectra suggest the existence of single emitting species.

Thus the spectroscopic properties of samples prepared by Method III are superior to those prepared by other two methods. The single lifetime values in the range of 1.12 $1.42 \mathrm{~ns}$ of STB-3 in these samples are an indication of the existence of a single fluorescent species.

\subsection{Laser Study}

When the blocks prepared by each method containing STB-3 dye with varied concentrations were subjected to laser studies by pumping them with nitrogen laser (337.1 $\mathrm{nm}$ ) in the transverse dye laser cavity with pump frequency of $1.67 \mathrm{~Hz}$, the laser emission was observed from samples with higher concentration $\left(5.51 \times 10^{18} \mathrm{~cm}^{-3}\right)$ Method I samples, but the output dies within $4-5$ pulses of the pump laser. Whereas lasing action could not be obtained for Method I and Method II samples. One of the reasons for not obtaining lasing action can be because of very short life time; which is very different from $4 \mathrm{~ns}$ the pulse duration of nitrogen laser. Also the $10^{18} \mathrm{~cm}^{-3}$ concentrations of dye molecules may not be adequate and pump energy of nitrogen laser may not be sufficient for showing lasing action.

\section{Conclusions}

Laser dye STB-3 could be embedded successfully in sol-gel glass samples prepared by all three methods. Laser dye STB-3 incorporated in sol-gel glass samples showed extinction coefficient and quantum yield values comparable to that in methanolic solution. The absorption and fluorescence wavelengths showed slight blue shift in case of dye doped solids as compared to that in the solution. This can be combined effect of higher refractive index of solids and environment surrounding the dye molecule.

Though very poor lasing action was observed in case of samples prepared by Method I, the photophysical performance was found to be best in method III samples.

\section{References}

[1] Schafer, F.P. (1990) Dye Lasers. Springer Verlag, Berlin.

[2] Duarte, F.J. and Hillman, L.W. (1990) Dye Laser Principles. Academic, New York.

[3] Deshpande, A.V. and Mhatre, V.B. (1996) Correlation of Lasing and Fluorescence Properties of Bromine Containing Fluorescein Derivatives. Journal of Luminescence, 65, 313-319. http://dx.doi.org/10.1016/0022-2313(95)00091-7

[4] Reynolds, G.A. and Drexhage, K.H. (1975) New Coumarin Dyes with Rigidized Structure for Flashlamp-Pumped Dye Lasers. Optics Communications, 13, 222-225. http://dx.doi.org/10.1016/0030-4018(75)90085-1

[5] Ramalingam, A. and Vijila, C. (1999) A Study of Spectral and Gain Characteristics of Sub- 
stituted Amino Coumarins under Nitrogen Laser Excitation. Journal of Molecular Liquids, 81, 237-244. http://dx.doi.org/10.1016/S0167-7322(99)00054-9

[6] Giffin, S.M., McKinnie, I.T., Wadsworth, W.J., Woolhouse, A.D., Smith, G.J. and Haskell, T.G. (1999) Solid State Dye Lasers Based on 2-Hydroxyethyl Methacrylate and Methyl Methacrylate Co-Polymers. Optics Communications, 161, 163-170.

http://dx.doi.org/10.1016/S0030-4018(99)00008-5

[7] Hermes, R.E., Allik, T.H., Chandra, S. and Hutchinson, J.A. (1993) High Efficiency Pyrromethene Doped Solid State Dye Lasers. Applied Physics Letters, 63, 877-879. http://dx.doi.org/10.1063/1.109887

[8] Altman, J.C., Stone, R.E., Dunn, B. and Nishida, F. (1991) Solid-State Laser Using a Rhodamine-Doped Silica Gel Compound. IEEE Photonics Technology Letters, 3, 189-190. http://dx.doi.org/10.1109/68.79748

[9] Canva, M., Georges, P., Perelgritz, J.F., Brun, A., Chaput, F. and Boilot, J.P. (1995) Perylene- and Pyrromethene-Doped Xerogel for a Pulsed Laser. Applied Optics, 34, 428-432. http://dx.doi.org/10.1364/AO.34.000428

[10] Maslyukov, A., Sokolov, S., Kaivola, M., Nyholm, K. and Popov, S. (1995) Solid-State Dye Laser with Modified Poly(methyl methacrylate)-Doped Active Elements. Applied Optics, 34, 1516-1518. http://dx.doi.org/10.1364/AO.34.001516

[11] Costela, A., Florido, F., Gercia-Moreno, I., Duchowicz, R., Amat-Guerri, F., Figuera, J.M. and Sastre, R. (1995) Solid-State Dye Lasers Based on Copolymers of 2-Hydroxyethyl Methacrylate and Methyl Methacrylate Doped with Rhodamine 6G. Applied Physics B, 60, 383-389. http://dx.doi.org/10.1007/BF01082275

[12] Costela, A., Gercia-Moreno, I., Figuera, J.M., Amat-Guerri, F. and Sastre, R. (1996) Solid State Dye Lasers Based on Polymers Incorporating Covalently Bonded Modified Rhodamine 6G. Applied Physics Letters, 68, 593-595. http://dx.doi.org/10.1063/1.363255

[13] Ye, C., Lam, K.S., Chik, K.P., Lo, D. and Wang, K.H. (1996) Output Performance of a Dye Doped Sol Gel Silica Laser in the Near UV. Applied Physics Letters, 69, 3800-3802. http://dx.doi.org/10.1063/1.117109

[14] Hu, W., Ye, H., Li, C., Jiang, Z. and Zhou, F. (1997) All-Solid-State Tunable DCM Dye Laser Pumped by a Diode-Pumped Nd:YAG Laser. Applied Optics, 36, 579-583. http://dx.doi.org/10.1364/AO.36.000579

[15] Chandra, S., Allik, T.A., Hutchinson, J.A., Fox, J. and Swin, C. (1997) Tunable Ultraviolet Laser Source Based on Solid-State Dye Laser Technology and $\mathrm{CsLiB}_{6} \mathrm{O}_{10}$ Harmonic Generation. Optics Letters, 22, 209-211. http://dx.doi.org/10.1364/OL.22.000209

[16] Duarte, F.J., Costela, A., Gercia-Moreno, I., Sastre, R., Ehrlich, J.J. and Tylor, T.S. (1997) Dispersive Solid-State Dye Laser Oscillators. Optical and Quantum Electronics, 29, 461472. http://dx.doi.org/10.1023/A:1018551432627

[17] Rahn, M.D., King, T.A. and Hamblett, A.I. (1997) Photostability Enhancement of Pyrromethene 567 and Perylene Orange in Oxygen-Free Liquid and Solid Dye Lasers. Applied Optics, 36, 5862-5871. http://dx.doi.org/10.1364/AO.36.005862

[18] Faloss, M., Canva, M., Georges, P., Brun, A., Chaput, F. and Boilot, J.P. (1997) Toward Millions of Laser Pulses with Pyrromethene- and Perylene-Doped Xerogel. Applied Optics, 36, 6760-6763. http://dx.doi.org/10.1364/AO.36.006760

[19] Knobbe, E.T., Dunn, B., Fuqua, P.D. and Nishida, F. (1990) Laser Behavior and Photostability Characteristics of Organic Dye Doped Silicate Gel Materials. Applied Optics, 29, 2729-2733.

[20] McKiernan, J.M., Yamanaka, S.A. Dunn, B. and Zink, J.I. (1990) Spectroscopy and Laser 
Action of Rhodamine 6G Doped Aluminosilicate Xerogels. The Journal of Physical Chemistry, 94, 5652-5654. http://dx.doi.org/10.1021/j100378a007

[21] Lo, D., Parris, J.E. and Lawless, J.L. (1992) Multi-Megawatt Superradiant Emissions from Coumarin-Doped Sol-Gel Derived Silica. Applied Physics B, 55, 365-367. http://dx.doi.org/10.1007/BF00333082

[22] Lo, D., Parris, J.E. and Lawless, J.L. (1993) Laser and Fluorescence Properties of Dye-Doped Sol-Gel Silica from $400 \mathrm{~nm}$ to $800 \mathrm{~nm}$. Applied Physics B, 56, 385-390. http://dx.doi.org/10.1007/BF00324537

[23] Bauer, R.K., Balter, A., Kowalczyk, A. and Jung, C. (1980) Some Luminescence Properties of the Laser Dye Stilbene 3. Zeitschrift fur Naturforschung A, 35, 1319-1324. http://dx.doi.org/10.1515/zna-1980-1210

[24] Fukuda, M. and Mito, K. (2000) Laser Oscillation of Energy Transfer Solid-State Dye Laser with a Thin-Film Ring Resonator. Japanese Journal of Applied Physics, 39, 3470-3471. http://dx.doi.org/10.1143/JJAP.39.3470

[25] Weissbeck, A., Langhoff, H. and Beck, A. (1995) Lasing and Fluorescence Properties of Dye-Doped Xerogel. Applied Physics B, 61, 253-255. http://dx.doi.org/10.1007/BF01082044

[26] Lam, K.S. and Lo, D. (1998) Lasing Behavior of Sol-Gel Silica Doped with UV Laser Dyes. Applied Physics B, 66, 427-430. http://dx.doi.org/10.1007/s003400050413

[27] Ye, C., Lam, K.S., Lam, S.K. and Lo, D. (1997) Dye-Doped Sol-Gel Derived Silica Laser Tunable from $352 \mathrm{~nm}$ to $387 \mathrm{~nm}$. Applied Physics B, 65, 109-111. http://dx.doi.org/10.1007/s003400050257

[28] Lam, S.K., Zhu, X.L. and Lo, D. (1999) Single Longitudinal Mode Lasing of Coumarin-Doped Sol-Gel Silica Laser. Applied Physics B, 68, 1151-1153. http://dx.doi.org/10.1007/s003400050760

[29] Arbeloa, T.L., Arbeloa, F.L., Tapia, M.J. and Arbeloa, I.L. (1993) Hydrogen-Bonding Effect on the Photophysical Properties of 7-Aminocoumarin Derivatives. Journal of Physical Chemistry, 97, 4704-4707. http://dx.doi.org/10.1021/j100120a024

[30] Jones, G., Jackson, W.R. and Halpern Chem, A.M. (1980) Medium Effects on Fluorescence Quantum Yields And Lifetimes for Coumarin Laser Dyes. Physics Letters, 72, 391-395. http://dx.doi.org/10.1016/0009-2614(80)80314-9

[31] Jones, G., Jackson, W.R., Yoo Choi, C. and Bergmark, W.R. (1985) Solvent Effects on Emission Yield and Lifetime for Coumarin Laser Dyes. Requirements for a Rotatory Decay Mechanism. Journal of Physical Chemistry, 89, 294-300. http://dx.doi.org/10.1021/j100248a024

[32] Gustavsson, T., Cassara, L., Gulbinas, V., Mialocq, J.C., Pommeret, S., Sorgius, M. and van der Meulen, P. (1998) Femtosecond Spectroscopic Study of Relaxation Processes of Three Amino-Substituted Coumar in Dyes in Methanol and Dimethyl Sulfoxide. Journal of Physical Chemistry A, 102, 4229-4245. http://dx.doi.org/10.1021/jp980282d

[33] Kunjappu, J.T. (1993) Photophysical Properties of Five Laser Dyes (C120, Cl, C102, C1F and C153) in Homogeneous, Surfactant and Membrane Media. Journal of Photochemistry and Photobiology A: Chemistry, 71, 269-273. http://dx.doi.org/10.1016/1010-6030(93)85009-W

[34] Costela, A., Gercia-Moreno, I., Barosso, J. and Sastre, R. (1998) Studies on Laser Action from Polymeric Matrices Doped with Coumarin 503. Applied Physics B, 67, 167-173. http://dx.doi.org/10.1007/s003400050489

[35] Suratwala, T., Gardlund, Z., Davidson, K., Uhlmann, D.R., Watson, J., Bonilla, S. and Peyghambarian, N. (1998) Silylated Coumarin Dyes in Sol-Gel Hosts. 2. Photostability and 
Sol-Gel Processing. Chemistry of Materials, 10, 199-209.

http://dx.doi.org/10.1021/cm970340s

[36] Deshpande, A.V. and Namdas, E.B. (2000) Correlation between Lasing and Photophysical Performance of Dyes in Polymethylmethacrylate. Journal of Luminescence, 91, 25-31. http://dx.doi.org/10.1016/S0022-2313(00)00210-6

[37] Costela, A., Gercia-Moreno, I., Barosso, J. and Sastre, R. (1998) Laser Performance of Coumarin 540A Dye Molecules in Polymeric Host Media with Different Viscosities: From Liquid Solution to Solid Polymer Matrix. Journal of Applied Physics, 83, 650-660. http://dx.doi.org/10.1063/1.366755

[38] Deshpande, A.V. and Panhalkar, R.R. (2002) Spectroscopic Properties of Coumarin 2 in $\mathrm{HCl}$ and $\mathrm{HNO}_{3}$ Catalysed Sol-Gel Glasses. Journal of Luminescence, 96, 185-193. http://dx.doi.org/10.1016/S0022-2313(01)00218-6

[39] Deshpande, A.V. and Kumar, U. (2002) Molecular Forms of Coumarin-307 in Sol-Gel Glasses. Journal of Fluorescence, 16, 679-687. http://dx.doi.org/10.1007/s10895-006-0109-5

[40] Deshpande, A.V., Jathar, L.V. and Rane, J.R. (2008) Effect of Matrix Treatment on Spectroscopic Properties of $\mathrm{HCl}$ Catalysed Sol-Gel Glasses Containing Coumarin Laser Dyes. Journal of Fluorescence, 19, 607-614. http://dx.doi.org/10.1007/s10895-008-0451-x

[41] Del Monte, F., Mackenzie, J.D. and Levy, D. (2000) Rhodamine Fluorescent Dimers Adsorbed on the Porous Surface of Silica Gels. Langmuir, 16, 7377-7382. http://dx.doi.org/10.1021/la000540+

[42] Del Monte, F. and Levy, D. (1999) Identification of Oblique and Coplanar Inclined Fluorescent J-Dimers in Rhodamine 110 Doped Sol-Gel-Glasses. Journal of Physical Chemistry $B, 103,8080-8086$. http://dx.doi.org/10.1021/jp991491g

[43] Del Monte, F. and Levy, D. (1998) Formation of Fluorescent Rhodamine B J-Dimers in Sol-Gel Glasses Induced by the Adsorption Geometry on the Silica Surface. Journal of Physical Chemistry B, 102, 8036-8041. http://dx.doi.org/10.1021/jp982396v

[44] Leveau, B., Herlet, N., Livage, J. and Sanchez Chem, C. (1993) Optical Properties of a Near-Infrared Dye Laser Incorporated Inside Sol-Gel Matrices. Chemical Physics Letters, 206, 15-20. http://dx.doi.org/10.1016/0009-2614(93)85509-M

[45] Del Monte, F. and Levy, D. (1995) Near-Infrared Dyes Encapsulated in Sol-Gel Matrixes. Chemistry of Materials, 7, 292-298. http://dx.doi.org/10.1021/cm00050a010

[46] Levy, D. and Avnir, D. (1988) Effects of the Changes in the Properties of Silica Cage along the Gel/Xerogel Transition on the Photochromic Behavior of Trapped Spiropyrans. Journal of Physical Chemistry, 92, 4734-4738. http://dx.doi.org/10.1021/j100327a035

[47] Narang, U. and Bright, F. (1996) Conformational Flexibility of 1,3-Bis(1-Pyrenyl)Propane Throughout the Sol-Gel to Xerogel Process. Chemistry of Materials, 8, 1410-1414. http://dx.doi.org/10.1021/cm960040v

[48] Innozenci, P., Kozuka, H. and Yoko, T. (1997) Fluorescence Properties of the Ru(bpy) ${ }_{3}{ }^{2+}$ Complex Incorporated in Sol-Gel-Derived Silica Coating Films. Journal of Physical Chemistry $B, 101,2285-2291$. http://dx.doi.org/10.1021/jp970004z

[49] Martini, I., Hartland, G.V. and Kamat, P.V. (1997) Ultrafast Photophysical Investigation of Cresyl Violet Aggregates Adsorbed onto Nanometer-Sized Particles of $\mathrm{SnO}_{2}$ and $\mathrm{SiO}_{2}$. Journal of Physical Chemistry B, 101, 4826-4830. http://dx.doi.org/10.1021/jp9702964

[50] Innocenzi, P., Kozuka, H. and Yoko, T. (1996) Dimer-to-Monomer Transformation of Rhodamine 6G in Sol-Gel Silica Films. Journal of Non-Crystalline Solids, 201, 26-36. http://dx.doi.org/10.1016/0022-3093(95)00620-6 
Submit or recommend next manuscript to SCIRP and we will provide best service for you:

Accepting pre-submission inquiries through Email, Facebook, LinkedIn, Twitter, etc. A wide selection of journals (inclusive of 9 subjects, more than 200 journals)

Providing 24-hour high-quality service

User-friendly online submission system

Fair and swift peer-review system

Efficient typesetting and proofreading procedure

Display of the result of downloads and visits, as well as the number of cited articles

Maximum dissemination of your research work

Submit your manuscript at: http://papersubmission.scirp.org/

Or contact njgc@scirp.org 